\title{
Metadata Correction: Patient Empowerment During the COVID-19 Pandemic by Ensuring Safe and Fast Communication of Test Results: Implementation and Performance of a Tracking System
}

Gunnar Völkel $^{1^{*}}, \mathrm{PhD}$; Axel Fürstberger ${ }^{1 *}, \mathrm{PhD}$; Julian D Schwab ${ }^{1^{*}}, \mathrm{PhD}$; Silke D Werle ${ }^{1^{*}}, \mathrm{PhD}$; Nensi Ikonomi ${ }^{1^{*}}$, MSc; Thomas Gscheidmeier ${ }^{2}$, MSc; Johann M Kraus ${ }^{1}$, PhD; Alexander Groß ${ }^{1}$, PhD; Martin Holderried ${ }^{3}$, MD, PhD; Julien Balig ${ }^{1}$, MSc; Franz Jobst ${ }^{4}$, MSc; Peter Kuhn ${ }^{5}$, PhD; Klaus A Kuhn ${ }^{6}, \mathrm{PhD}$; Oliver Kohlbacher ${ }^{7}, \mathrm{PhD}$; Udo X Kaisers $^{4}$, MD; Thomas Seufferlein ${ }^{8^{*}}, \mathrm{MD}$; Hans A Kestler ${ }^{1^{*}}, \mathrm{PhD}$

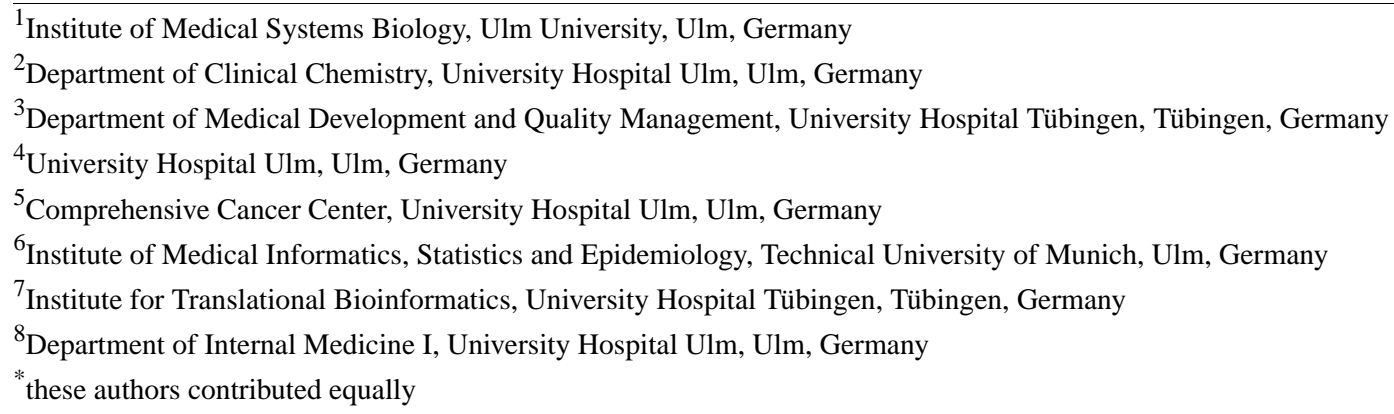

\section{Corresponding Author:}

Hans A Kestler, PhD

Institute of Medical Systems Biology

Ulm University

Albert-Einstein-Allee 11

Ulm, 89081

Germany

Phone: 4973150024500

Fax: 4973150024501

Email: hans.kestler@uni-ulm.de

\section{Related Article:}

Correction of: https://www.jmir.org/2021/6/e27348

(J Med Internet Res 2021;23(6):e31253) doi: 10.2196/31253

In "Patient Empowerment During the COVID-19 Pandemic by Ensuring Safe and Fast Communication of Test Results: Implementation and Performance of a Tracking System" (J Med Internet Res 2021;23(6):e27348) the authors noted one error.

In the originally published manuscript, the author Nensi Ikonomi was not credited as an equal contributor. This has been corrected to show that Gunnar Völkel, Axel Fürstberger, Julian D Schwab,
Silke D Werle, Nensi Ikonomi, Thomas Seufferlein, and Hans A Kestler all contributed equally to the manuscript.

The correction will appear in the online version of the paper on the JMIR Publications website on June 21, 2021, together with the publication of this correction notice. Because this was made after submission to PubMed, PubMed Central, and other full-text repositories, the corrected article has also been resubmitted to those repositories. 
This is a non-peer-reviewed article. Submitted 15.06.21; accepted 16.06.21; published 21.06.21.

Please cite as:

Völkel G, Fürstberger A, Schwab JD, Werle SD, Ikonomi N, Gscheidmeier T, Kraus JM, Groß A, Holderried M, Balig J, Jobst F, Kuhn P, Kuhn KA, Kohlbacher O, Kaisers UX, Seufferlein T, Kestler HA

Metadata Correction: Patient Empowerment During the COVID-19 Pandemic by Ensuring Safe and Fast Communication of Test Results: Implementation and Performance of a Tracking System

J Med Internet Res 2021;23(6):e31253

URL: https://www.jmir.org/2021/6/e31253

doi: $\underline{10.2196 / 31253}$

PMID:

(C) Gunnar Völkel, Axel Fürstberger, Julian D Schwab, Silke D Werle, Nensi Ikonomi, Thomas Gscheidmeier, Johann M Kraus, Alexander Groß, Martin Holderried, Julien Balig, Franz Jobst, Peter Kuhn, Klaus A Kuhn, Oliver Kohlbacher, Udo X Kaisers, Thomas Seufferlein, Hans A Kestler. Originally published in the Journal of Medical Internet Research (https://www.jmir.org), 21.06.2021. This is an open-access article distributed under the terms of the Creative Commons Attribution License (https://creativecommons.org/licenses/by/4.0/), which permits unrestricted use, distribution, and reproduction in any medium, provided the original work, first published in the Journal of Medical Internet Research, is properly cited. The complete bibliographic information, a link to the original publication on https://www.jmir.org/, as well as this copyright and license information must be included. 